\title{
LncRNA CTBP1-AS2 sponges miR-216a to upregulate PTEN and suppress endometrial cancer cell invasion and migration
}

\author{
Qing-an-zi Wang, Yongxiu Yang ${ }^{*}$ and Xiaolei Liang
}

\begin{abstract}
Background: Although IncRNA CTBP1-AS2 has been functionally analyzed only in ciomyoc, hypertrophy and diabetes, analysis of TCGA dataset revealed its downregulation in endometrial carcinon, (ES), indicating its
involvement in EC.

Results: In this study we found that CTBP1-AS2 was downregulated in EC. 216a might form base pairs with CTBP1-AS2 based on RNA-RNA interaction, $m$ bwas confirmed by luciferase activity assay. Interestingly, upregulation of PTEN was observed after 1 -AS2) overexpression. Transwell assay showed that CTBP1-AS2 and PTEN overexpression led to decreased car Cet C, 1 invasion and migration and reduced enhancing effects of miR-216a on cell invasion and migration. It was kncwn that miR-216a targeted PTEN.

Conclusion: Therefore, CTBP1-AS2 may sponge miR-216a to up ulate PTEN, thereby suppressing endometrial
\end{abstract} cancer cell invasion and migration.

Keywords: CTBP1-AS2, Endometrial carcinoma, SU ivol. miR-2) Ja, PTEN

\section{Background}

Endometrial carcinoma (EC) is the moc comm $\mathrm{l}_{\mathrm{y}} \mathrm{di}-$ agnosed gynecologic malignancies t' at develops from endometrium [1]. EC mostly affects enopau/al females and causes a series symptoms includir. olvic pain, pain with urination and vaginal ble [2]. Obesity is the main risk factor for EC [3]. Be ides, nat, other factors, such as high blood pressu. exce sive estrogen exposure and diabetes, are aloo 'os orelated with the occurrence of EC [3, 1. Base on the clinical symptoms and risk factors, fan, detectio, 1 of EC is possible in some cases with the ope on of physical examinations, such as pelvi examination, endometrial biopsy, magnetic resonance ang ind so on $[5,6]$. However, these exams

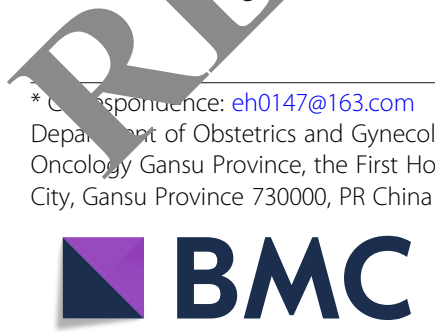
Oncology Gansu Province, the First Hospital of Lanzhou University, Lanzhou City, Gansu Province 730000, PR China are not practical for all cases and early detection rate of EC is still low.

Molecular alterations are critical players in the pathogenesis of EC [7]. Functional analysis of molecular regulators in EC would facilitate the development of novel anti-EC approaches, such as targeted therapies, which aim to suppress cancer development by regulating cancer-related gene expression $[8,9]$. Long non-coding RNAs (lncRNAs) are not involved in protein synthesis but can regulate gene expression at multiple levels to participate in human diseases, including cancers [10]. LncRNAs interact with cancer-related proteins and other non-coding RNAs, such as miRNAs [11]. Therefore, regulating the expression of cancer-related lncRNAs will also contribute to cancer treatment. CTBP1-AS2 has been characterized as a critical player in type 2 diabetes and cardiomyocyte hypertrophy [12, 13]. However, its involvement in cancer biology is unknown. We analyzed the expression of CTBP1-AS2 by TCGA dataset, and

(c) The Author(s). 2020 Open Access This article is licensed under a Creative Commons Attribution 4.0 International License, which permits use, sharing, adaptation, distribution and reproduction in any medium or format, as long as you give appropriate credit to the original author(s) and the source, provide a link to the Creative Commons licence, and indicate if changes were made. The images or other third party material in this article are included in the article's Creative Commons licence, unless indicated otherwise in a credit line to the material. If material is not included in the article's Creative Commons licence and your intended use is not permitted by statutory regulation or exceeds the permitted use, you will need to obtain permission directly from the copyright holder. To view a copy of this licence, visit http://creativecommons.org/licenses/by/4.0/ The Creative Commons Public Domain Dedication waiver (http://creativecommons.org/publicdomain/zero/1.0/) applies to the data made available in this article, unless otherwise stated in a credit line to the data. 
observed downregulation of CTBP1-AS2 in EC tissues. In addition, CTBP1-AS2 is predicted to interact with miR-216a, which can target PTEN to promote cancer development [14]. This study was therefore carried out to analyze the interactions among CTBP1-AS2, miR216a and PTEN in EC.

\section{Methods}

\section{Tissue acquisition}

Paired EC tumor and non-tumor tissues were collected from 62 EC patients (47 to 68 years, $58.1 \pm 4.7$ years) through fine needle biopsy. All patients were enrolled at the First Hospital of Lanzhou University between January 2012 and January 2014. This study was approved by aforementioned hospital Ethics Committee. All tissue specimens were confirmed by performing histopathological exam. All the patients were excluded from other severe clinical disorders. All patients were diagnosed for the first time and no recurrent EC cases were included. All patients provided informed consent.

\section{Treatment and follow-up}

Patients were treated with different therapeutic approaches, such as chemotherapies, radio therapies and surgeries. According to AJCC staging criteria the $62 \mathrm{pa}-$ tients included 12, 21, 18 and 11 cases at clinical stage $\mathbf{r}$, II, III and IV, respectively. A 5-year follow-up wh ve formed on all patients since the date of admisston. patients' survival was recorded and all pleted follow-up.

\section{Cells and transfections}

HEC-1 (ATCC, USA) human EC cell wa used. Dulbecco's modified Eagle's medil (90\%) was mixed with $10 \%$ FBS to prepare cell culture mf un $\Lambda$. Cells were cultivated at $37^{\circ} \mathrm{C}$ in a $5^{\circ} \quad \mathrm{P}_{2}$ in ubator to reach about $85 \%$ confluence.

Constructions $\mathrm{C}$ C 1-AS2 and PTEN expression vectors were $\mathrm{p}_{-}$rmed us, $\mathrm{g}$ pcDNA3.1 vector as backbone. MiR-216a mic and negative control (NC) miRNA vere bought from Sigma-Aldrich. HEC-1 cells were tra $f_{f}$-ied with CTBP1-AS2 or PTEN expression vec (10 \%) or miR-216a mimic (40 nM) using lipoctar ine 20,00 (Invitrogen). Cells were transfected with N mins or empty pcDNA3.1 vector to be used as NC I's. Control cells(C group) were untransfected. Subsequent experiments were carried out $48 \mathrm{~h}$ later.

\section{Luciferase activity assay}

Construction of CTBP1-AS2 vector was performed using pGL3 luciferase reporter vector (basic, Promega Corporation) as backbone. Lipofectamine 2000 (Invitrogen) was used to transfect HEC-1 cells with the combination of CTBP1-AS2 vector+miR-216a (miR-216a group) or the combination of CTBP1-AS2 vector+NC miRNA (NC group). Measurement of luciferase activity was performed at $48 \mathrm{~h}$ post-transfection using Luciferase Assay System (BPS Bioscience).

\section{RNA extraction}

Extractions of total RNAs and miRNAs from ti ue samples and HEC-1 cells were performed using Azo (Sigma-Aldrich) and High Pure miRNA Isolatio. v/it (Sigma-Aldrich), respectively. Genomic NA vas removed using gDNA eraser (Takay). Na Drop 2000 (Thermo Scientific) was used to heasure RNA concentrations and 6\% urine-PAGE gel v used lo check RNA integrity.

\section{RT-qPCR assay}

BlazeTaq $^{\mathrm{Tm}}$ One-Step SYBK reen RT-qPCR Kit (Genecopoeia) was used measure the expression levels of CTBP1-AS2 a mRNA. All-in-One ${ }^{\mathrm{rm}}$ miRNA qRT-PCR Reagen it/Genecopoeia) was used to measure the ex cion levels of miR-216a. GAPDH was used as the encogenyus control of CTBP1-AS2 and PTEN mRNA. U6 was used as endogenous control of miR21. All steps were completed following manufacturer's instru tions. Three replicates were included in each ex$\mathrm{P}$ inent and $\Delta \Delta \mathrm{Ct}$ method was used to calculate fold changes of the levels of gene expression.

\section{Western blot}

Total protein extractions from HEC-1 cells were performed using RIPA solution (Invitrogen) and protein samples were quantified using BCA assay (Invitrogen). Protein samples were incubated with boiling water for $15 \mathrm{~min}$ to achieve protein denaturation. SDS-PAGE gel (10\%) was used to separate different proteins, and PVDF membranes were used to transfer proteins. PBS with non-fat milk (5\% non-fat milk) was used to block membranes, followed by using GAPDH (ab9485, Abcam) and PTEN (ab31392, Abcam) primary antibodies to incubate with the membranes for $15 \mathrm{~h}$ at $4{ }^{\circ} \mathrm{C}$. After that, membranes were used to incubate with HRP Goat AntiRabbit (IgG) secondary antibody (ab97051, Abcam) for another $2 \mathrm{~h}$ at room temperature. Signals were produced using ECL (Sigma-Aldrich) and were normalized using Quantity One software.

\section{Transwell assays}

Transwell filters ( $8 \mu \mathrm{m}$; Dojindo) were used to perform Transwell invasion and migration assays using Matrigel-coated membranes and un-coated membranes, respectively. HEC-1 cells were transferred to the upper Transwell chamber $(5000$ cells in $0.1 \mathrm{ml}$ per well), and the lower chambers contained a mixture of $20 \%$ FBS and $80 \%$ medium. Cells were 
cultivated at $37^{\circ} \mathrm{C}$ for $12 \mathrm{~h}$. After that, lower surface of membranes was stained with crystal violet $(0.1 \%)$ for $20 \mathrm{~min}$. Invading and migrating cells were observed under a light microscope.

\section{Statistical analysis}

All aforementioned experiments were performed in triplicates and data were expressed as mean values. Paired $t$ test was used to compare EC and non-tumor tissues. Luciferase activity was compared by unpaired t test. Comparisons among multiple groups were performed using ANOVA (one-way) and Tukey test. The 62 patients were grouped into high and low CTBP1AS2 level groups (31 patients for each group). Survival curves were plotted using GraphPad Prism 6 software. Comparison of survival curves was performed using log-rank test. $P<0.05$ was statistically significant.

\section{Results}

CTBP1-AS2 was downregulated in EC and correlated with poor survival

TCGA dataset was explored to analyze the expression on CTBP1-AS2. It was observed that the level of CTPAAS2 expression was lower in EC tissues than i noltumor tissues (7.69 vs. 10.00). what's more, enpres n levels of CTBP1-AS2 in both EC and non-t. or tissuc from the total 62 patients were measured ay po rming RT-qPCR. Paired t test showed that 6 xpression le els of CTBP1-AS2 were significantly lower in EC tissues than in non-tumor tissues (Fig. 1a, $p<0.0$ Sur ival curves were plotted for both high a low CIDP1-AS2 level groups $(n=31)$. Log-rank test na showed that patients in low CTBP1-A level group experienced significantly lower over sur val ra.e (Fig. 1b).
CTBP1-AS2 and miR-216a could interact with each other The possible base pairs formed by CTBP1-AS2 and miR-216a were predicted using IntaRNA. It was observed that CTBP1-AS2 and miR-216a could form strong base pairing (Fig. 2a). Luciferase activity assay was performed by transfecting HEC-1 cells $\mathrm{wi}^{\mathrm{i}^{+h}}$ the combination of CTBP1-AS2 vector + miR-21 a $\left(\mathrm{miR}_{-}\right.$ 216a group) or the combination of CTBPA-A vector+NC miRNA (NC group). It was /observea at relatively luciferase activity was signim tly lo ver in miR-216a group than in NC group (1ig. $-\quad b 20.05$ ).

\section{CTBP1-AS2 overexpression res'ylte n upre julation of} PTEN

HEC-1 cells were trans ${ }^{\text {ected }}$ i CTBP1-AS2 expression vector or miR-216, vimic to analyze the interactions between CTBP1-AS nd miR-216a. Expression levels of CTBP $1-A$ and miR-216a were significantly increased at 40 insfection compared to $C$ and NC groups (Fig. 3. $\longleftarrow 0.05$ ), indicating successful transfection. a ring to $\mathrm{C}$ and $\mathrm{NC}$ groups, CTBP1-AS2 and miR-2 $6 \mathrm{a}$ o erexpression did not significantly affect the expression of each other (Fig. 3b). This observation Sus ted that CTBP1-AS2 might be an endogenous pon of miR-216a. Therefore, qPCR and western blot e performed to analyze the effects of CTBP1-AS2 and miR-216a overexpression on the expression of PTEN at mRNA (Fig. 3c) and protein (Fig. 3d) levels, respectively. It was observed that miR-216a overexpression led to downregulated PTEN $(p<0.05)$. CTBP1-AS2 overexpression led to upregulation of PTEN $(p<0.05)$.

\section{CTBP1-AS2 interacted with miR-216a/PTEN axis to suppress EC cell invasion and migration}

Comparing to $\mathrm{C}$ group, miR-216a overexpression caused the increased invasion (Fig. 4a) and migration (Fig. 4b) rates of HEC-1 cells $(p<0.05)$. In addition, CTBP1-AS2
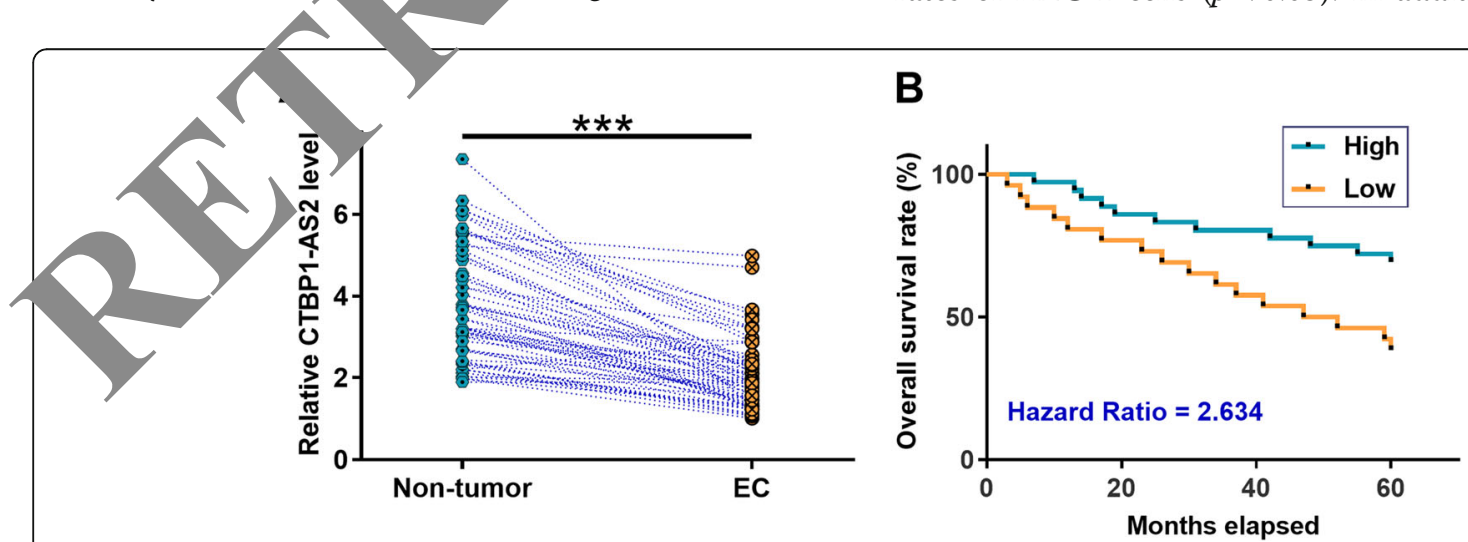

Fig. 1 CTBP1-AS2 was downregulated in EC and correlated with poor survival. Expression levels of CTBP1-AS2 in both EC and non-tumor tissues from the 62 patients were measured by performing RT-qPCR. All PCR reactions were expressed as mean values and were compared by paired $t$ test $(\mathbf{a}) .{ }^{* * *}, p<0.001$. The 62 patients were grouped into high and low CTBP1-AS2 level groups (31 patients for each group). Survival curves were plotted using GraphPad Prism 6 software. Comparison of survival curves was performed using log-rank test (b) 


\section{A}

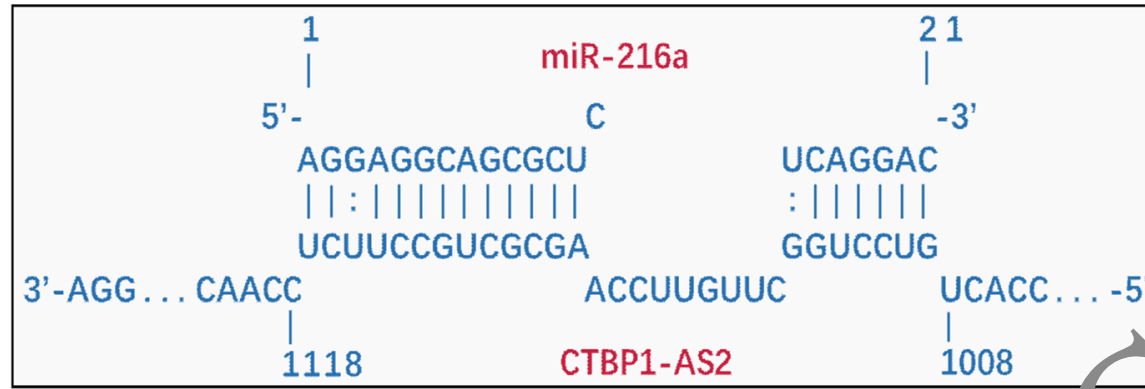

B
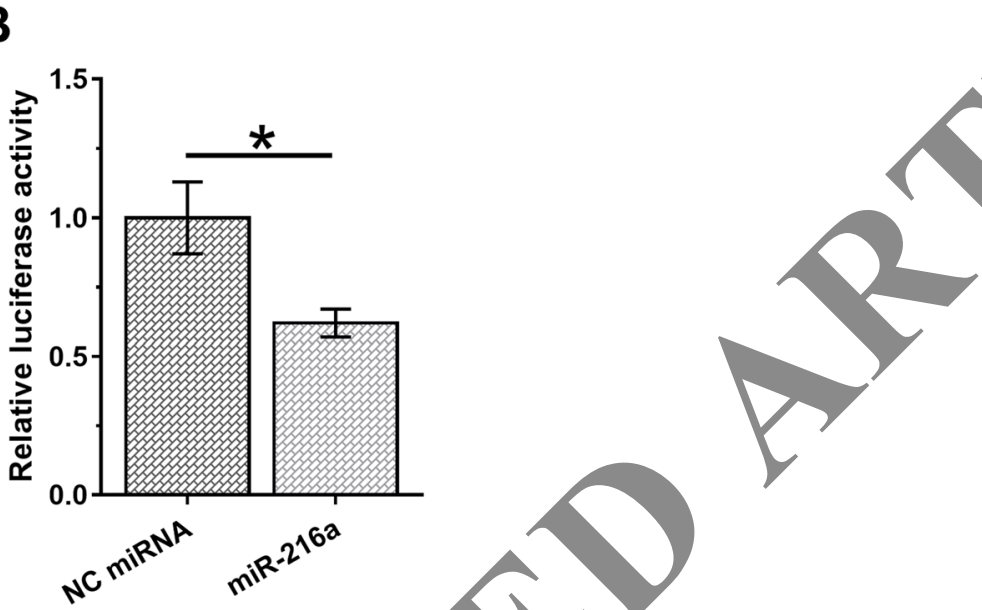

Fig. 2 CTBP1-AS2 and miR-216a could interact with each other. possib base pairs formed by CTBP1-AS2 and miR-216a were predicted using IntaRNA (a). Luciferase activity assay was performe by trans no AEC-1 cells with the combination of CTBP1-AS2 vector+miR-216a (miR216a group) or the combination of CTBP1-AS2 vector A iRNA (NCgroup). Mean values of 3 biological replicates were calculated and compared by unpaired t test $(\mathbf{b}) .{ }^{*}, p<0.05$

and PTEN overexpression led to de ced cancer cell invasion and migration and rec enhancing effects of miR-216a on cell invasion and nigyar $\Lambda(p<0.05)$.

\section{Discussion}

We analyzed the irrolv ent of CTBP1-AS2 in EC. We found that $\mathrm{CT} / \mathrm{AS} 2 \mathrm{w}$ downregulated in EC and had predictive val for EC. In addition, CTBP1-AS2 might harbor miR-2, 6a to upregulate PTEN, thereby inhibitil. b_inv sion and migration of EC cells.

$\mathrm{P}$ ious ud hes have reported the involvement of TB1 -AS2 in type 2 diabetes and cardiomyocyte h) rtropriy $[12,13]$. Decreased expression level of $\mathrm{CTb}$ AS2 was closely correlated with the occurrence of type 2 diabetes and cardiomyocyte hypertrophy among Iranian population [12]., Luo et al. reported that CTBP1-AS2 could be induced by $\mathrm{Sp} 1$ and it could stabilize TLR4 through the interaction with FUS to participate in the disease progression [13]. Our study is the first to report the involvement of CTBP1-AS2 in cancer biology. We reported that CTBP1-AS2 was downregulated in EC and its overexpression led to inhibiting cancer cell invasion and migration. Therefore, CTBP1AS2 was likely a tumor suppressor in EC. It was worth noting that by analyzing TCGA dataset we noticed the altered expression of CTBP1-AS2 in EC. The involvement of CTBP1-AS2 in other cancers remains to be further analyzed.

With the development of novel anti-cancer therapies, survival of early stage EC has been significantly improved [15]. However, the therapeutic effects of advanced EC remain unsatisfactory owing to the lack of effective anti-cancer therapies [16]. As an alternative approach, accurate prognosis may improve patients' survival by guiding the selection of therapeutic approaches and care programs. Our study proved that downregulation of CTBP1-AS2 was closely correlated with the poor survival of EC patients. However, our study is limited by the small sample size. More studies with bigger sample size are needed to further test the reliability.

The function of miRNA sponge is to inhibit the function of the miRNA, but may or may not regulate the expression of the miRNA. Our data supports the idea that CTBP1-AS2 may be an endogenous sponge of miR- 
A

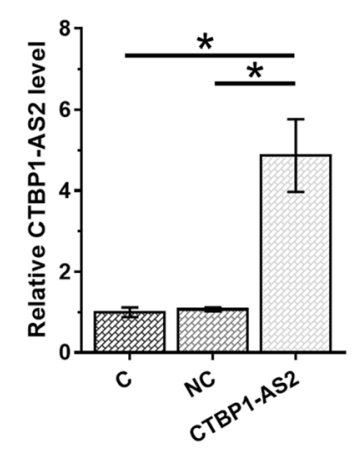

C

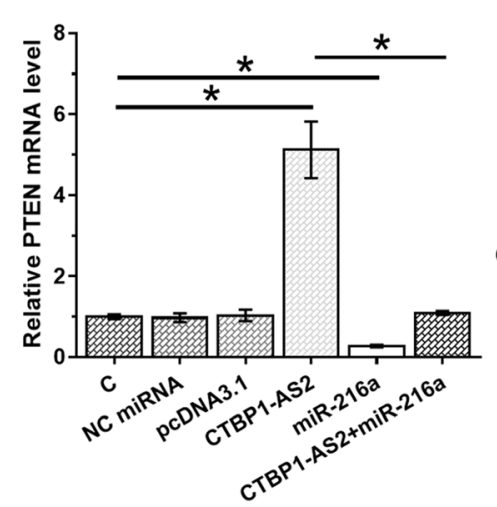

B
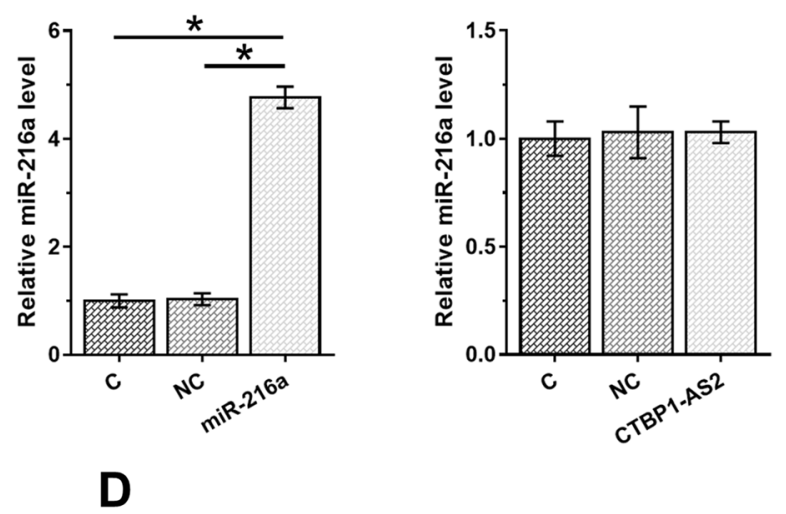

PTEN

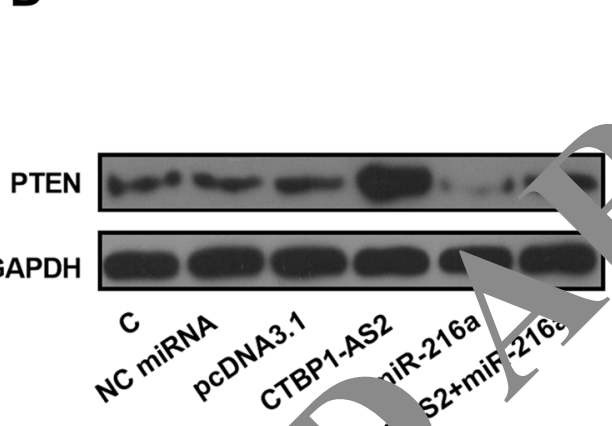

Fig. 3 CTBP1-AS2 overexpression resulted in upregulation of mimic to analyze the interactions between CTBP1-AS2 an a miR-2 iv verexpression of CTBP1-AS2 and miR-216a was confirmed at $48 \mathrm{~h}$ posttransfection (a). The effects of CTBP1-AS2 and miR-216 a rexpressio on expression of each other were analyzed by GPCR (b). QPCR and western blot were performed to analyze the effects of CTb, $\$$ S2 and miR-216a overexpression on the expression of PTEN at mRNA (c) and protein (d) levels, respectively. Mean values of 2 plorogical rep, ates were calculated and compared by unpaired t test. ${ }^{*}, p<0.05$
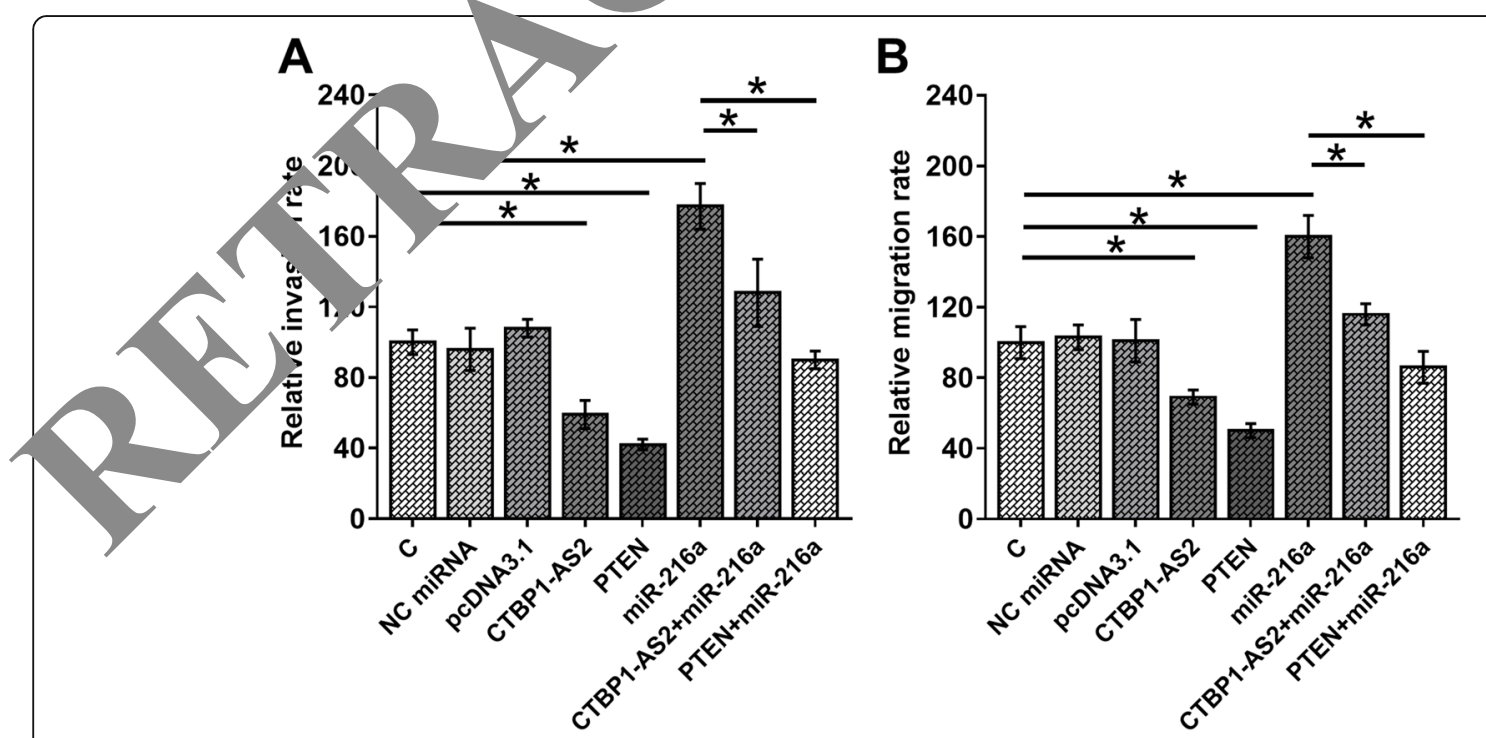

Fig. 4 CTBP1-AS2 interacted with miR-216a/PTEN axis to suppress EC cell invasion and migration. Transwell assays were performed to analyze the effects of CTBP1-AS2, miR-216a and PTEN overexpression on the invasion (a) and migration (b) of HEC-1 cells. Mean values of 3 biological replicates were calculated and compared by unpaired t test. ${ }^{*}, p<0.05$ 
216a. This is based on the observation that CTBP1-AS2 and miR-216a cannot regulate the expression of each other. In addition, CTBP1-AS2 overexpression reduced the effects of miR-216a overexpression on PTEN expression, thus resulted in reducing EC cells invasion as well as migration. PTEN plays tumor suppressive roles in different types of cancers mainly by inducing cell apoptosis and suppressing cancer metastasis [14]. Therefore, PTEN may serve as the downstream effector of CTBP1AS2/miR-216a pathway to suppress the metastasis of EC. However, other mechanisms may mediate the interactions between CTBP1-AS2 and miR-216a, future studies are still needed.

In conclusion, upregulated of CTBP1-AS2 in EC could sponge miR-216a to upregulate the expression of PTEN, thereby suppressing endometrial cancer cell migration and invasion.

\section{Abbreviations}

EC: Endometrial carcinoma; IncRNAs: Long non-coding RNAs

\section{Acknowledgements}

Not applicable.

\section{Authors' contributions}

All authors contributed to data analysis, drafting or revising the article, gave final approval of the version to be published, and agree to be accountable for all aspects of the work.

\section{Funding}

Not applicable.

\section{Availability of data and materials}

The analyzed data sets generated during the stud corresponding author on reasonable request.

\section{Ethics approval and consent to participate}

The present study was approved by the Ethics Comm the Maternity and Child Care Center of Liuzhou. The rese has been carried out in accordance with the World Medical Associa jion a ration of Helsinki. All patients and healthy volunteers $n$ ided wrien informed consent prior to their inclusion within the stu

\section{Consent for publicatic 1}

Not applicable.

\section{Competing in}

The author deglare that they have no competing interests. degare that

Received: 14 emb 2019 Accepted: 24 March 2020

Paols d onlih 15 April 2020

Re inces

1. $\quad \mathrm{W}$, Ellenson LH. Molecular genetics of endometrial carcinoma. Annu Re) Pathol. 2019;14:339-67.

2. Cantrell LA, Blank SV, Duska LR. Uterine carcinosarcoma: a review of the literature. Gynecol Oncol. 2015;137(3):581-8.

3. Yang HP, Wentzensen $\mathrm{N}$, Trabert $\mathrm{B}$, et al. Endometrial cancer risk factors by 2 main histologic subtypes: the NIH-AARP diet and health study. Am J Epidemiol. 2012;177(2):142-51.

4. Haidopoulos D, Simou M, Akrivos N, et al. Risk factors in women 40 years of age and younger with endometrial carcinoma. Acta Obstet Gynecol Scand. 2010;89(10):1326-30.

5. Colas E, Perez C, Cabrera S, et al. Molecular markers of endometrial carcinoma detected in uterine aspirates. Int J Cancer. 2011;129(10):2435-44.
6. Ballester M, Dubernard G, Lécuru F, et al. Detection rate and diagnostic accuracy of sentinel-node biopsy in early stage endometrial cancer: a prospective multicentre study (SENTI-ENDO). Lancet Oncol. 2011;12(5):46976.

7. Yeramian A, Moreno-Bueno G, Dolcet X, et al. Endometrial carcinoma: molecular alterations involved in tumor development and progression. Oncogene. 2013;32(4):403-13.

8. Dedes K, Wetterskog D, Ashworth A, et al. Emerging therapeutic aryets in endometrial cancer. Nat Rev Clin Oncol. 2011;8(5):261-71.

9. Salvesen HB, Haldorsen IS, Trovik J. Markers for individualised endometrial carcinoma. Lancet Oncol. 2012;13(8):e353-61.

10. Fatica A, Bozzoni I. Long non-coding RNAs: new playe 's in cell differentiation and development. Nat Rev Genet. 201. (1):7-21.

11. Shi X, Sun M, Liu H, et al. Long non-coding RNA new the study of human diseases. Cancer Lett. 2013.739(2):159-66.

12. Erfanian Omidvar M, Ghaedi $H$, Kazerouni $F$ t al. Clinical sighificance of long noncoding RNA VIM-AS1 and CTEP1-A expressio in type 2 diabetes. J Cell Biochem. 2019;120, 5-2

13. Luo $X, H$ e S, Hu Y, et al. Sp1-ind ined $L$, IA CTBP1-AS2 is a novel regulator in cardiomyocyte vertrophy b, Macting with FUS to stabilize TLR4. Cardiovasc Pathol. 2019, 1-9.

14. Xia H, Ooi LLPJ, Hui KM. MicroR\、6a/217-induced epithelialmesenchymal tranc argets PTE, and SMAD7 to promote drug resistance and $r$ vurren of liver cancer. Hepatology. 2013;58(2):629-41.

15. Wong AT, Rinee et al. Patterns of adjuvant radiation usage and survival outcon 'or stage I endometrial carcinoma in a large hospitalbased d art. Gynecol icol. 2017;144(1):113-8.

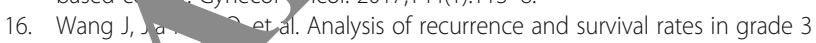
endometr pid/ena,metrial carcinoma. Oncol Lett. 2016;12(4):2860-7.

\section{Pu. Sher's Note}

Vature remains neutral with regard to jurisdictional claims in maps and institutional affiliations.
Ready to submit your research? Choose BMC and benefit from:

- fast, convenient online submission

- thorough peer review by experienced researchers in your field

- rapid publication on acceptance

- support for research data, including large and complex data types

- gold Open Access which fosters wider collaboration and increased citations

- maximum visibility for your research: over $100 \mathrm{M}$ website views per year

At BMC, research is always in progress.

Learn more biomedcentral.com/submissions 